\title{
Rearrangement of the tubulin and actin cytoskeleton during programmed cell death in Drosophila salivary glands
}

\author{
Jana Jochová ${ }^{1,2,3,4}$, Zahra Zakeri ${ }^{2}$ and Richard A. Lockshin \\ 1 Department of Biological Sciences, St. John's University, Jamaica, NY 11432 , \\ USA \\ 2 Department of Biology, Queens College and the Graduate Center of the City \\ University of New York, Flushing, NY 11371, USA \\ 3 Present address: Department of Biology, Queen's University, Kingston, \\ Ontario, Canada K7L 3N6 \\ ${ }^{4}$ corresponding author
}

Received 5.4.96; revised 20.6.96; accepted 28.6.96

Edited by G. Melino

\begin{abstract}
During larva-to-pupa metamorphosis Drosophila salivary glands undergo programmed cell death by autophagocytosis. Although ultrastructure of Drosophila salivary glands has been extensively studied in the past, little is known about mechanism of programmed cell death, especially the role of the cytoskeleton. In this paper we describe changes in microtubule and actin filament network compared to the progress of DNA fragmentation and redistribution of acid phosphatase. In feeding and wandering larvae microtubules and actin filaments form regular networks localized mostly along the plasma membrane. The first major rearrangement of microtubules and actin filaments occurred when larvae everted spiracles and the glands shifted their secretion from saliva to mucoprotein glue (stage L1). Microtubule cytoskeleton became denser and actin filaments concentrated along cell boundaries. At the same time nuclei flattened and migrated into the microtubule-rich layer near the basal membrane. In late prepupae (8-10 h after P1) the microtubule network became fainter, and actin filaments appeared frequently deeper in cytoplasm, gradually concentrating around nuclei.

Simultaneously large patches of acid phosphatase activity surrounded nuclei and shortly thereafter chromosomal DNA began to fragment. During the final collapse of the gland (early pupae, $13.5 \mathrm{~h}$ after formation of white puparium) cellular fragments and autophagic vacuoles contained a continuous F-actin lining and the microtubule network displayed signs of extensive degradation. The results are consistent with the hypothesis that, in Drosophila salivary glands, extensive autophagic activities target nuclei for degradation; that this process occurs late in the course of programmed cell death; and that it directly involves cytoskeletal structures which are altered far earlier during the course of cell death.
\end{abstract}

Keywords: microtubules, actin filaments, programmed cell death, Drosophila salivary glands
Abbreviations: $P C D$, programmed cell death; ICE, interleukin$1 \beta$-converting enzyme; DAPI, diamidino-2-phenylindole

\section{Introduction}

Programmed cell death (PCD) is defined by the presence of a program that allows unwanted cells to be quickly eliminated in a controlled apoptotic manner (Raff et al, 1994). Genetic studies in Caenorhabditis elegans and Drosophila melanogaster have suggested the existence of an evolutionarily conserved program required for the induction of PCD (Hengartner, 1994; Steller, 1995 ). Apoptosis is usually characterized by shrinkage and fragmentation of cytoplasm, together with a coalescence of chromatin into a single mass and a sometimes delayed internucleosomal fragmentation of the DNA (Raff et al, 1994; Martin et al, 1994; Bortner et al, 1995; Majno and Joris, 1995; Zakeri et al, 1995 for recent reviews). Later in the process, in most vertebrate cells, dehydration and fragmentation of the cytoplasm and nuclei give rise to apoptotic bodies. These latter are quickly removed through phagocytosis by macrophages or neighboring cells (Wyllie et al, 1980). In metamorphosing insect tissues and some other tissues of epithelial origin the bulk of the cytoplasm is degraded in lysosome-derived autophagic vacuoles (Beaulaton and Lockshin, 1982; Zakeri et al, 1995). In different systems, ICE-like proteases (Yuan et al, 1993; Kumar, 1995) play an important role in the protease activation cascade leading to apoptotic collapse of cells (Martin and Green, 1995). The substrates of proteolysis include lamin B (Voelkel-Johnson et al, 1995), involved in maintaining integrity of nuclear structure, and cytoskeletal proteins such as actin, fodrin and Gas2 (Martin et al, 1995; Brancolini et al, 1995; Martin and Green, 1995). Thus the cytoskeleton may be an important component of the first phases of apoptosis.

Reorganization of the cytoskeleton represents an important part of the apoptotic changes in cell morphology. Blebbing of vertebrate cells, a major indicator of ongoing apoptosis, is clearly associated with changes in the actin filament system, including redistribution or elimination of actin-binding proteins (Dayton et al, 1981; Jewell et al, 1982; Nicotera and Orrenius, 1992). Formation of apoptotic bodies in late stages of apoptosis requires actin filament assembly and can be blocked by inhibitors of actin polymerization (Cotter et al, 1992). Experimentallyinduced disruption of microtubules can trigger apoptosis in several mammalian cell lines (Martin and Cotter, 1990a; Tsukidate et al, 1993; Takano et al, 1993) and loss of microtubules has been observed during apoptosis of HL-60 cells and $\beta$-amyloid-induced apoptosis of neural cells (Martin and Cotter, 1990b; Watt et al, 1994). Others have reported abundant microtubules and increased overall tubulin immunofluorescence during apoptosis in some 
human cell lines (Pittman et al, 1994). However, in these studies one cannot rule out the possibility that the rearrangements seen are simply reflections or consequences of the well-known morphological changes.

Metamorphosing Drosophila salivary glands first secrete a silk-like glue protein and then undergo PCD. Both of these activities involve the cytoskeleton. Secretory epithelial cells in general require intact cytoskeleton for their function. Actin filaments support the asymmetric shape of the cells as well as microvilli at the apical surface of epithelial cells (Carraway and Carraway, 1989). Microtubules mediate transport of membraneous compartments during secretion (Schroer and Sheetz, 1991) and abundant microtubules are present in salivary glands of Drosophila larvae (Riparbelli et al, 1993). Although various aspects of the intracellular morphology of Drosophila salivary glands during development have been extensively studied in the past (Poels et al, 1971; Harrod and Kastritsis, 1972; von Gaudecker, 1974; Thomopoulos et al, 1989, 1992; Riparbelli et al, 1993), remarkably little is known about the mechanism of PCD of the gland cells and especially the role of cytoskeleton in this process. This paper describes changes in organization of tubulin and actin cytoskeleton during cell death. These changes occur early and are associated with the progress of DNA fragmentation and redistribution of lysosomal acid phosphatase. The results are consistent with the hypothesis that in Drosophila salivary glands cytoskeletal rearrangements begin before extensive autophagic activities target nuclei for degradation late in the course of programmed cell death.

\section{Results}

\section{Alteration in tubulin organization}

Drosophila salivary glands start to autolyze immediately after the peak in their secretory activity at larva-to-pupa metamorphosis. We first analysed the microtubule system in active glands from third instar feeding and wandering larvae. Our observations were consistent with those of Riparbelli et al (1993). The tubulin immunofluorescence revealed a fine lacelike network of microtubules (Figure 1A). Abundant fluorescence near the lateral membranes sharply contrasted with low fluorescence background inside the cells, suggesting that the microtubules were concentrated along the lateral membranes and near the basal membrane of the gland. Double staining with DAPI revealed nuclei located mostly in the centers of the cells (Figure 1B). Higher magnification of the basal cortex

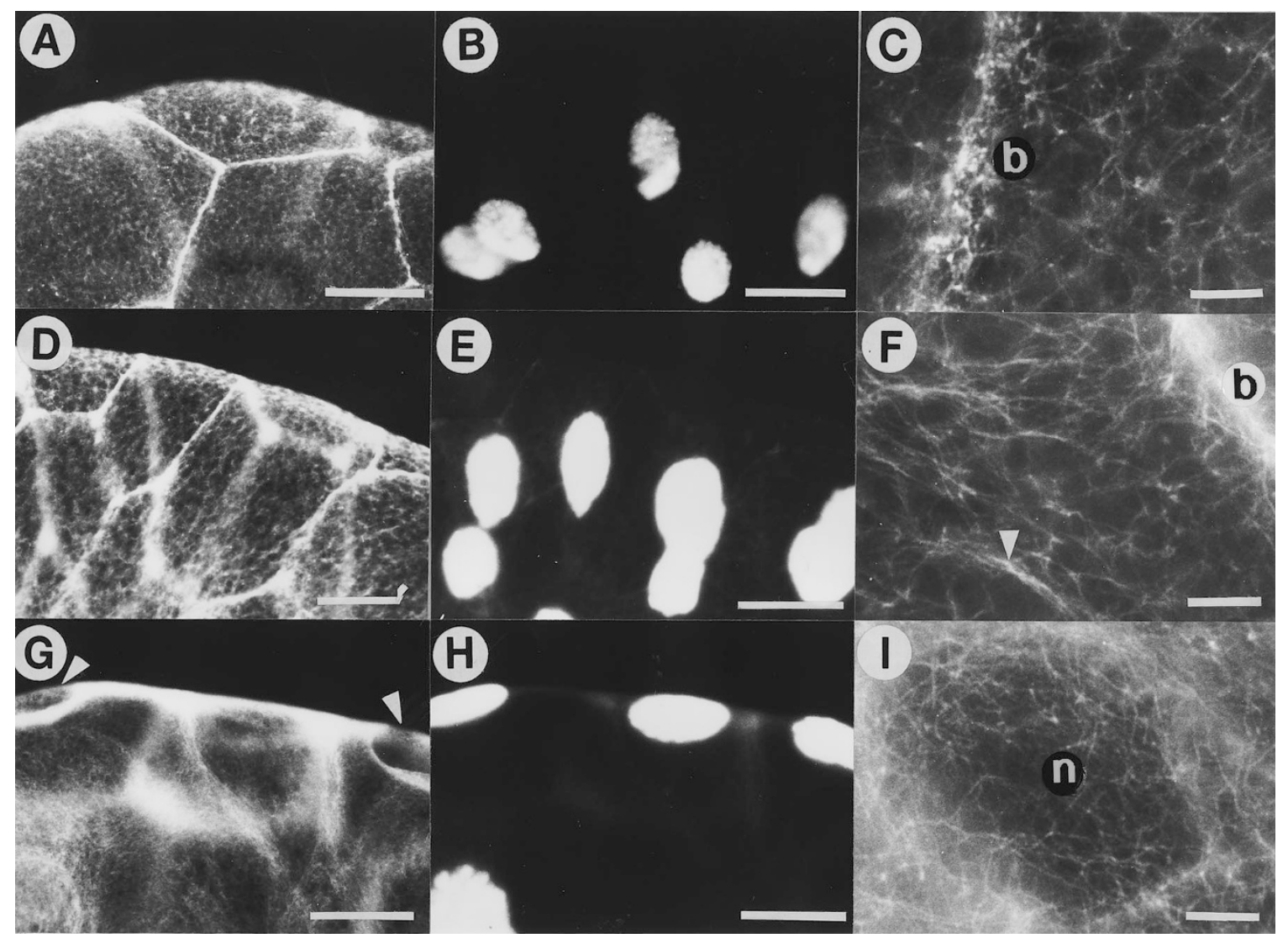

Figure 1 Double staining of microtubules $(A, D, G)$ and nuclei $(B, E . H)$ in Drosophila salivary glands. The left and center columns are duplicate exposures of the same specimens, and the right columns are enlargements to show details of microtubule network near the basal membrane $(C, F, I)$. Figures $A-C$ represent the gland of a feeding larva, D-F, a wandering larva, and $\mathrm{G}-\mathrm{I}$, a postfeeding (L1 stage) larva. Especially in the earlier stages, the cell boundaries are clearly delineated by the microtubules, as is seen in A and D. $b$ - lateral cell boundary, arrowheads - microtubule bundles (F) or, microtubule baskets around nuclei (G), $n$ - nucleus. Bars, $150 \mu \mathrm{m}$ (left and center columns), $20 \mu \mathrm{m}$ (right column). 
showed a pattern composed of interlaced bundles of microtubules separated in a geometric pattern by areas about $5-10 \mu \mathrm{m}$ in diameter (Figure 1C).

Although the glands isolated from wandering larvae were larger than those from feeding larvae, the pattern of tubulin staining and localization of nuclei remained largely unchanged. However, the microtubular network near the basal membrane acquired a coarser appearance and the bright fluorescence near the lateral membranes became more blurred. This could be best seen at lower magnifications (Figure 1D and E). At high magnification slightly thicker bundles of microtubules were seen (Figure 1F) but the overall structure of the network appeared unchanged.

After the larvae stopped crawling and everted spiracles (stage L1) the size of the glands peaked as the lumen became filled with secretion (not shown). During this stage intracellular morphology underwent pronounced changes. The microtubule network was now much denser. Increased tubulin fluorescence made the lace-like network almost unrecognizable at low magnification. At the same time the nuclei migrated towards the basal membrane, flattened and penetrated fully into the cortical layer of microtubules. Distinct microtubule baskets surrounding nuclei were regularly seen at this stage (Figure $1 G$ and $H$ ). The increase of the tubulin fluorescence was not due to increased background fluorescence caused by massive microtubule depolymerization since a dense network of intact microtubules was visible in the regions between nuclei and the plasma membrane (Figure 1I). At stage L2, when the bodies of larvae shortened, the baskets around nuclei became even more defined against the dense microtubule network along the basal membrane (Figure $2 \mathrm{~A}$ and $\mathrm{B})$. This pattern of microtubule organization remained virtually unchanged through the formation of the white puparium (stage $\mathrm{P} 1$, not shown).

Approximately $2 \mathrm{~h}$ after $\mathrm{P} 1$ shrinkage of the gland became increasingly apparent. As the gland shrank the nuclei located under the basal membrane often protruded outwards, resulting in an irregular wrinkled appearance of the gland surface (Figure 2C). The microtubular network did not display any apparent sign of extensive degradation (Figure 2D).

At $8 \mathrm{~h}$ after $\mathrm{P} 1$, while the gland continued to shrink, microtubules appeared to be as dense as the previous stages. Large dark spots corresponding to nuclei were clearly visible. However, smaller dark inclusions developed in the otherwise uninterrupted microtubular network (Figure $2 \mathrm{E})$. These areas were randomly scattered and often surrounded by layers of intense fluorescence, suggesting that they represented microtubular baskets around vacuolar structures similar to those around nuclei. At higher magnification (Figure 2F) the microtubular network was seen to be more regular and fainter than at the previous stages and seemed to display the first signs of disintegration. Again, the detailed structure was distinguishable only in the thin layer between the basal membrane and the nuclei. The apparent size of the pores in the network, as seen in the microscope, was now mostly well below $5 \mu \mathrm{m}$. Moreover, distinct thick microtubule bundles were no longer observable by fluorescence microscopy (Figure 1F).
At $13-14 \mathrm{~h}$ after $\mathrm{P} 1$, when the animals entered the stage of phanerocephalic pupae, the glands began to collapse. Only remnants of the glands could be isolated from the pupae and these consisted mainly of loosely attached highly vacuolated cells. The final degradation of the tissue proceeded asynchronously even in neighboring cells, so that many cells could be found with morphology typical for the preceding stage. Gradually, as the secretory epithelium disintegrated, the cells lost their original shape and turned into aggregations of spherical autophagic vacuoles. At low magnification the tubulin immunofluorescence revealed irregular staining of non-uniform intensity that surrounded nuclei or their fragments. These could still be seen as rounded dark spots within the cells (Figure $2 \mathrm{G}$ ). In some places relatively unimpaired stretches of microtubules could be found at higher magnification but the network was mostly substantially reduced (Figure $2 \mathrm{H}$ ). At the same time a high background of diffuse fluorescence suggested that the major proportion of microtubules was depolymerized. No distinct pattern was observable in the rounded cell fragments or apoptotic vacuoles.

\section{Reorganization of actin filaments}

In the glands isolated from feeding larvae F-actin stained with Rh-phalloidin was concentrated mainly along lateral cell boundaries and in the periluminal region but also near the basal surface of the gland. Here actin filaments formed irregularly shaped blebs and brightly fluorescent short thick bars (Figure $3 \mathrm{~A})$. The blebs were often arranged into elongated arrays oriented mainly perpendicular to the gland axis. The bars were also oriented mostly perpendicular to the gland axis and were dispersed randomly along the basal membrane of the gland cells. The bars were not seen at the extreme anterior end of the gland (not shown).

In wandering larvae the cortical actin pattern remained largely unchanged, displaying fine surface blebs and thick bars. Rh-phalloidin fluorescence in the periluminal region was even more intense than at the previous stage, as the lumen swelled and filled with secretion (Figure 3B).

Similar to tubulin immunofluorescence, Rh-phalloidin staining revealed a major change in the actin filament organization in the postfeeding larvae (stage L1). The network of the F-actin blebs and rods was no longer present but discrete patches and dots appeared instead under the basal membrane (Figure $3 \mathrm{C}$ ). These structures were either randomly distributed or clustered into larger groups. The clusters were also visible along lateral membranes, giving them a rough discontinuous appearance, in contrast to the smooth boundaries visible at earlier stages of metamorphosis. At stage L2 actin filament patches and dots were more concentrated near the lateral membranes. At this stage the lateral cell boundaries gave the brightest, though rough and discontinuous, Rhphalloidin fluorescence, (Figure 3D). This organization of actin filaments persisted through the stage P1 (not shown).

At $2 \mathrm{~h}$ after $\mathrm{P} 1$ the actin filament system still consisted of submembraneous patches and dots, although the intensity of the fluorescence near the lateral membranes considerably decreased. However, the F-actin staining also became 
detectable scattered deeper in the cytoplasm. It appeared mostly in the form of dots and patches similar to those under the cell surface, but at the same time a new type of spherical vacuolar structure, with a thin continuous layer of F-actin, was regularly seen (Figure $4 \mathrm{~A}$ and $\mathrm{B}$ ). At this stage these structures were rather small (ca. $5-20 \mu \mathrm{m}$ in diameter) and distributed randomly throughout the cytoplasm.

At $10 \mathrm{~h}$ after $\mathrm{P} 1$ few actin filament patches were visible along the basal membrane and the fluorescent labeling

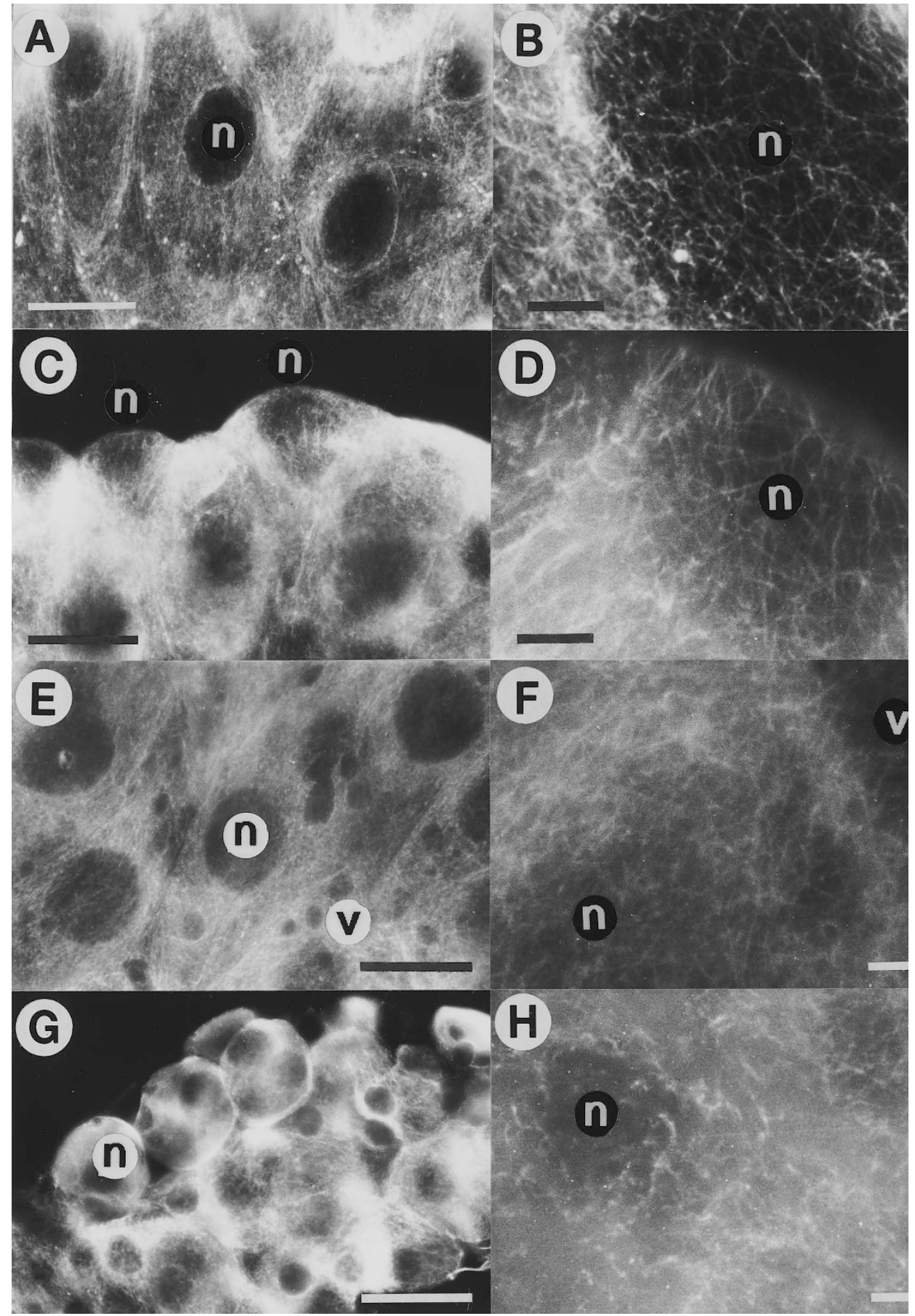

Figure 2 Microtubules in Drosophila salivary glands during later stages, lower magnification (left column) and details of microtubule network near the basal membrane (right column). (A,B) Stage L2. (C,D) $2 \mathrm{~h}$ after formation of white puparium (P1). (E,F) $8 \mathrm{~h}$ after P1. (G,H) $13.5 \mathrm{~h}$ after P1. $n-$ nucleus, $v-$ vacuoles, which appear at approximately $8 \mathrm{~h}$. Bars, $150 \mu \mathrm{m}$ (left column), $20 \mu \mathrm{m}$ (right column). The microtubule lattice is most clearly delineated where the apposition of the nucleus to the basal cell membrane leaves only a thin layer of cytoplasm. The haze seen in $\mathrm{H}$ could not be resolved under our optical conditions, leading us to conclude that it represented depolymerized microtubules. 
near the lateral membranes was noticeably reduced. Meanwhile, the fluorescence of the actin filament-coated organelles gradually became more and more conspicuous. Their number increased and they slightly increased in size (mostly $10-25 \mu \mathrm{m}$ ). The most striking change, however,

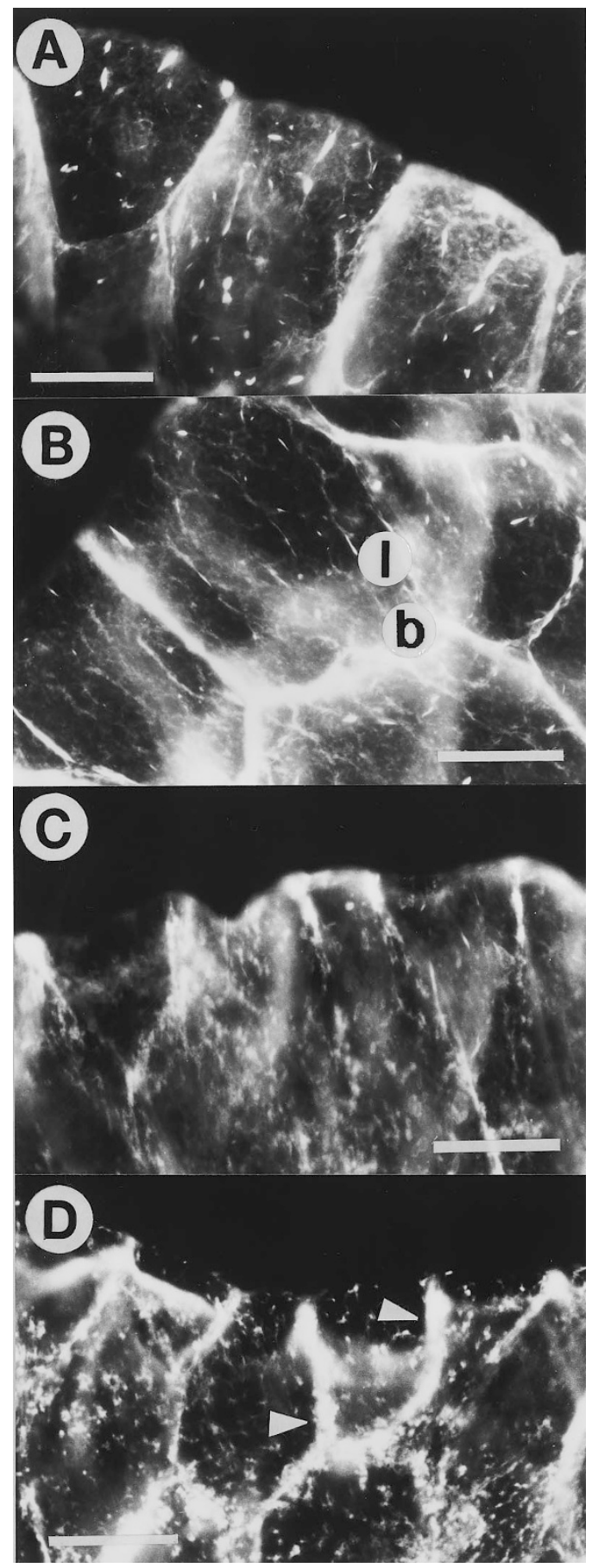

Figure 3 Actin filaments in Drosophila salivary glands. (A) Feeding larva, (B) Wandering larva, (C) Stage L1, (D) Stage L2. I - F-actin in periluminal region, $b$ - lateral cell boundary., arrowheads - lateral cell boundaries. Bars, $150 \mu \mathrm{m}$. Note the more ragged appearance of the actin beginning at $L 1$, and the subsequent aggregation near the cell boundaries. occurred in their localization. Whereas at the earlier stages their distribution was more or less random, within $10 \mathrm{~h}$ after P1 they accumulated around nuclei (Figure 4C and D). In the great majority of cells at this stage the actin filamentcoated organelles formed distinct rings around nuclei. The rings were either symmetrical or there was more material accumulated on one side of the nucleus.

Just before their final disintegration $(13-14 \mathrm{~h}$ after $\mathrm{P} 1)$ mostly only uneven continuous F-actin fluorescence was visible in the cells, often accompanied with larger irregular aggregates giving intense fluorescence staining. The surface of spherical cell fragments and autophagic vacuoles was associated with fluorescence that was similar to that observed in the intracellular F-actin-coated organelles found in the cytoplasm at late prepupae stage (Figure 4E). In contrast to the tubulin labeling, no apparent correlation between the pattern of actin filament distribution and the localization of nuclei could be found (Figure 4F).

\section{Accumulation of acid phosphatase activity}

The actin-coated vacuoles accumulated around nuclei approximately $10 \mathrm{~h}$ after $\mathrm{P} 1$, when the glands were rapidly shrinking. This suggests that these organelles might be directly involved in the process of advanced disintegration of the cells. One possibility is that these structures represent lysosomes or autophagic vacuoles, which are known to accumulate, activate, and reorganize during PCD in insect salivary glands (Lockshin, 1981; Halaby et al, 1994). Histochemical assays were performed for acid phosphatase as a marker activity of lysosomes to examine whether its distribution follows the same pattern as the distribution of actin-coated organelles. We found that, in the glands isolated from wandering larvae, acid phosphatase activity was localized into numerous discrete spots dispersed evenly throughout the cytoplasm (Figure 5A). Higher concentrations of the activity were observable along the lateral membranes. In the glands isolated from the animals $8.5 \mathrm{~h}$ after $\mathrm{P} 1$, the overall staining was much more intense, indicating considerably increased acid phosphatase activity. Although the dispersed spots were visible, most of the activity was at this stage concentrated around nuclei which were seen as areas bereft of reaction product close to the basal membrane. (Figure 5B). In contrast to the situation with the wandering larvae, the lateral cell boundaries were either associated with lighter staining than the rest of the cell or were not recognizable at all. Within another $3.5 \mathrm{~h}$ after $\mathrm{P} 1$ the overall staining became even more intense. The lateral cell boundaries were distinctly lighter as the bulk of the acid phosphatase activity moved towards nuclei and the cell boundaries were now visible as pale lines. At the same time, focusing through the cells revealed heavily stained spherical compartments surrounding the nuclei (Figure $5 \mathrm{C}$ ). At this and later stages the previously uniform pattern of staining became increasingly irregular, which probably reflected the fact that different portions of the gland underwent degradation at different rates. This was most prominent just before the final collapse of the gland, approximately $13-14 \mathrm{~h}$ after $\mathrm{P} 1$. At this stage individual cells differed in the distribution of acid phosphatase activity. The staining was concentrated to spots 
of various sizes, more or less concentrated around nuclei or their fragments. Cell fragments or released vacuoles gave the most intense continuous staining. Thus, the pattern of distribution of acid phosphatase activity closely followed the pattern of distribution of actin-coated organelles during the PCD of Drosophila salivary glands.

\section{Delayed DNA fragmentation during PCD}

In most systems, fragmentation of DNA molecules is one of the early signs of ongoing PCD (Bortner et al, 1995). However, in the hornworm Manduca sexta the DNA fragmentation is a late event (Zakeri et al, 1993). We wondered whether in degenerating Drosophila salivary glands the late accumulation of acid phosphatase around nuclei and the late nuclear degradation and fragmentation might also indicate delayed DNA fragmentation. For this purpose we employed the TUNEL technique, which enables specific fluorescent labeling of free ends of DNA molecules.
As a positive control, we treated glands isolated from wandering larvae with DNase I. These glands displayed intense labeling (Figure 6A). No label was detectable in untreated glands from the same stage which served as the negative control (not shown). The TUNEL labeling was not detectable in the glands from the early third instar through about $10 \mathrm{~h}$ after P1 (Figure 6B). Approximately $11 \mathrm{~h}$ after P1 more nuclei became visible as they started to accumulate the fluorescent label but the labeling remained rather weak (Figure 6C). The accumulation was not uniform and a markedly different intensity of the label could be detected even in neighboring cells. The fragmentation, however, tended to occur earlier in the cells near the anterior end, perhaps reflecting a gradient of progress of cell death or a differentiation in the physiology of the gland. In collapsing glands, around $13 \mathrm{~h}$ after P1, the labeling was distinct in all cells (Figure 6D), revealing essentially the same pattern as the staining of DNA by DAP1 (Figure 4F). Our results showed that in Drosophila salivary glands DNA fragmentation does

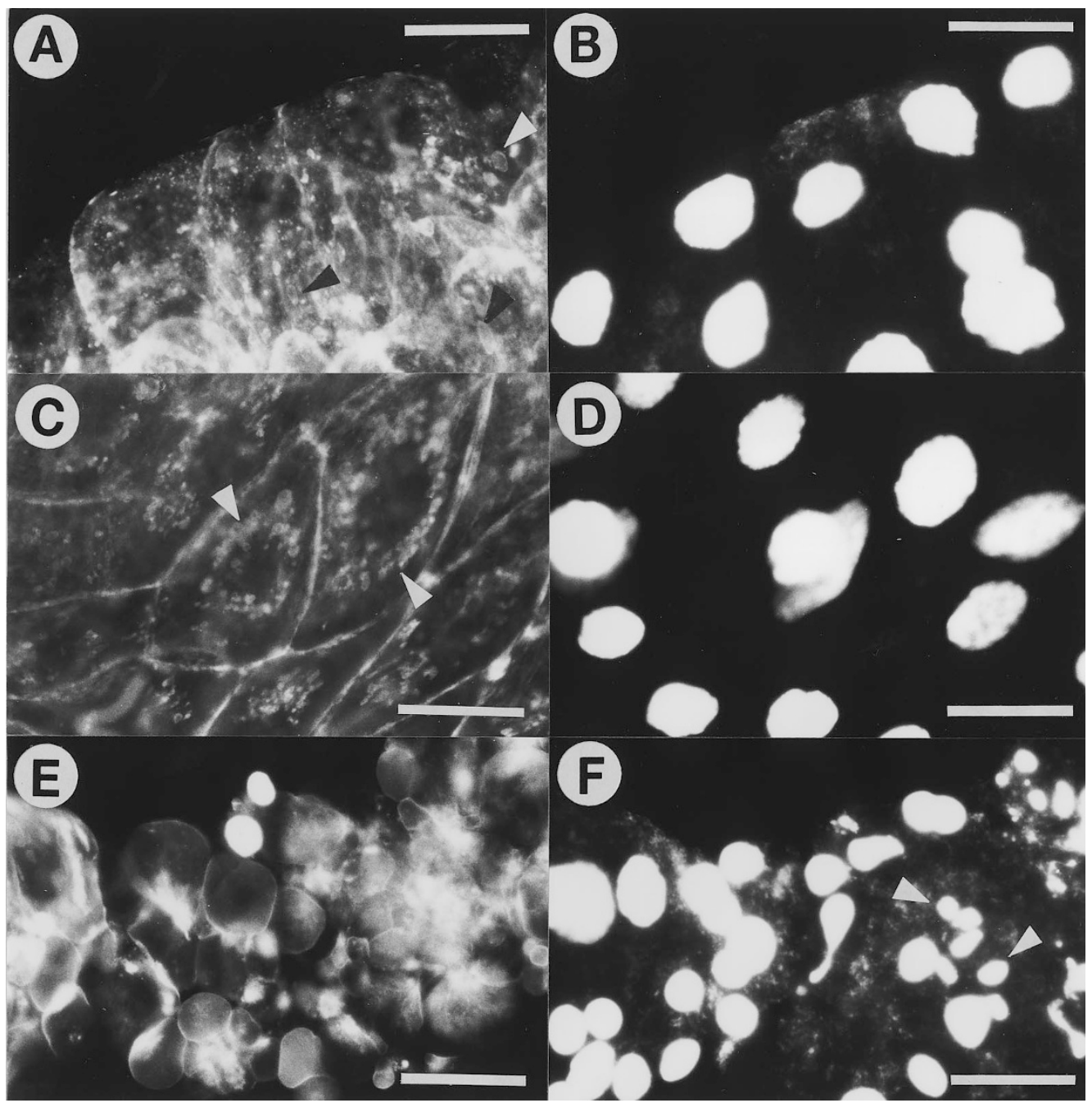

Figure 4 Double staining of actin filaments (left column) and nuclei (right column) in Drosophila salivary glands during later stages of metamorphosis. The sideby-side pictures are dual exposures of the same preparations. (A,B) $2 \mathrm{~h}$ after formation of white puparium (P1), (C,D) $10 \mathrm{~h}$ after P1, (E,F) $13.5 \mathrm{~h}$ after P1. Arrowheads - F-actin-coated vacuoles in A and C, nuclear fragments in F. Note the development of perinuclear vesicular aggregates of actin by $10 \mathrm{~h}$. Bars, $150 \mu \mathrm{m}$. 
not proceed to an extent detectable by fluorescence microscopy until the very late stages of metamorphosis, similar to what we have previously shown for the Manduca sexta labial gland (Zakeri et al, 1993).

\section{Discussion}

Organization of cytoskeleton is thought to be important for initiation and progression of apoptosis in different systems but from the limited data available to date its precise role is not understood. In this paper we concentrated on changes in the arrangement of microtubules and actin filaments during PCD in Drosophila salivary glands.

During the early and middle third instar stages (feeding and wandering larvae) microtubules formed a regular network concentrated mainly along the cell peripheries and actin filaments at the apex and near the lateral membranes. This pattern is typical for active Drosophila salivary glands in the middle third instar and has been described earlier by other investigators (Riparbelli et al, 1993).

At the onset of L1 the microtubules as well as actin filaments underwent major reorganization of their structure. The changes included an increase in the density of the microtubular network and dissolution of the regular arrangement of actin filament structures along the basal membrane. This is consistent with the findings of earlier ultrastructural studies that in L1 the gland cells undergo major restructuring as they switch from secretion of saliva to intense production of the mucoprotein glue (Harrod and
Kastritsis, 1972, von Gaudecker and Schmale, 1974; Thomopoulos et al, 1989; Riparbelli et al, 1993). It has been suggested (Riparbelli et al, 1993) that the microtubular network provides mechanical support of the gland epithelium rather than being directly involved in the secretion process. The reason for the increase in its density at this stage remains unclear. At the same time, the nuclei migrate towards the plasma membrane, flatten and become trapped in the baskets formed by the cortical microtubular network. It is plausible that the nuclei are displaced by the increasing number of large secretory granules that were originally dispersed over the cytoplasm and now start to fill the apical domain (Poels et al, 1971; Harrod and Kastritsis, 1972). Actin filaments are concentrated mainly at the apical domain, where they support the microvillar structure (Carraway and Carraway, 1989). Actin filaments near the basal membrane have also been interpreted as supporting infoldings of the membrane (Riparbelli et al, 1993). The infoldings are probably reduced or disappear as the gland swells prior the discharge of the glue. As the glue mucoprotein is discharged the glands start to shrink. This point marks the end of their functionality and the commitment to PCD.

During the initial stages of the larva-to-pupa metamorphosis the basic pattern of microtubule and actin filament distribution in the gland cells remains virtually unchanged. However, as the degradation proceeds some trends could be distinguished. First, the apparent increased density of the microtubule network does not diminish until a very late stage of PCD. Rather, the integrity of the network appears

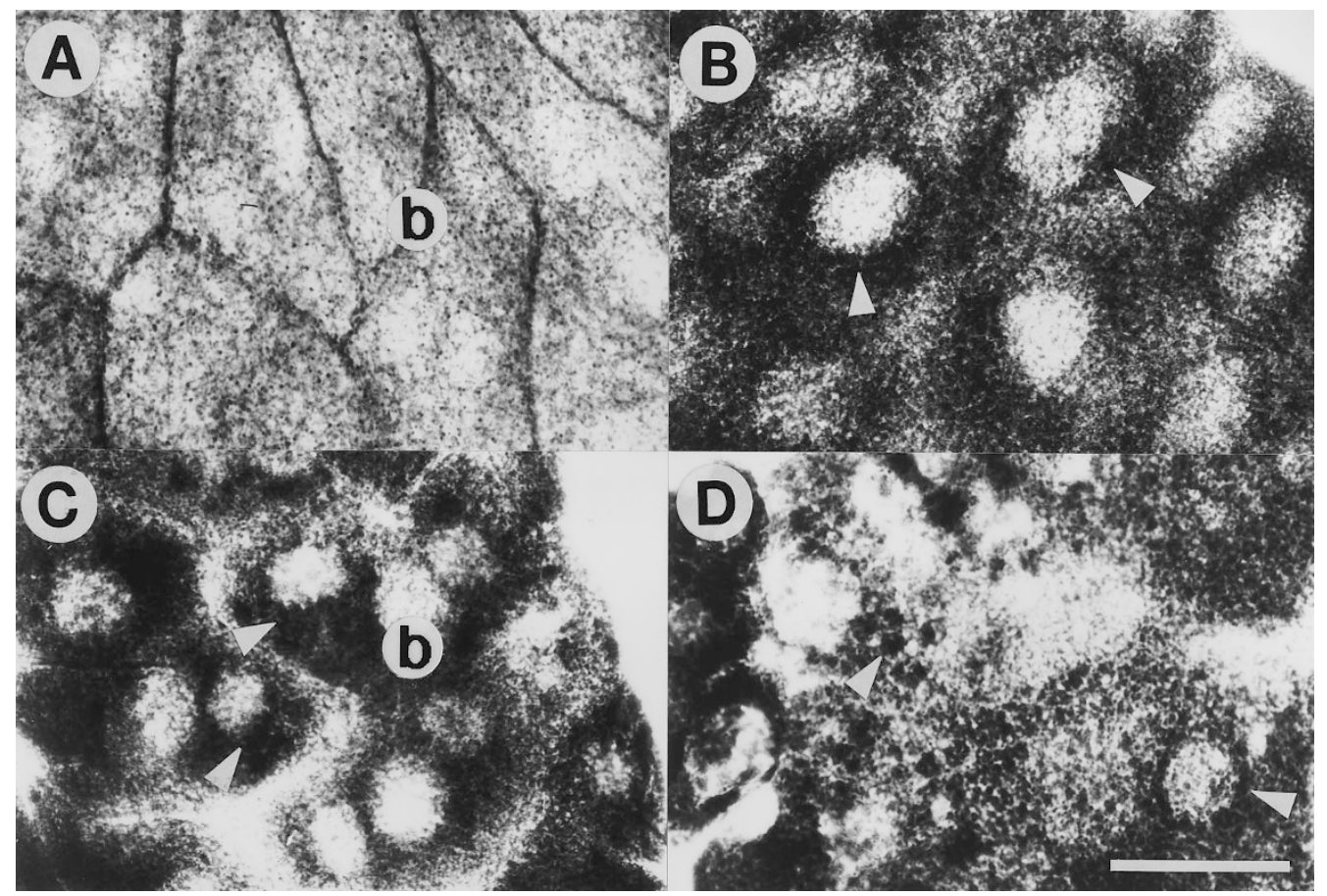

Figure 5 Histochemical detection of acid phosphatase in Drosophila salivary glands. (A) Wandering larva. (B) $8.5 \mathrm{~h}$ after P1. (C) $12 \mathrm{~h}$ after P1. (D) 13.5 h after P1. $b$ - cell boundaries, arrowheads - acid phosphatase activity in vacuoles concentrated around nuclei. Bar, $150 \mu \mathrm{m}$. Concentration of acid phosphatase delineates cell boundaries in feeding and wandering larvae, but thereafter the expansion and movement of the lysosomal compartment more clearly reveals the nuclei by their lack of reaction product. 
to slowly deteriorate from early on, as the thick microtubule bundles become scarcer and shorter fragments of individual microtubules are more and more frequent. Second, while the most prominent actin filament structure in the early third instar salivary glands is the lining of the apical membrane, in L2 and $\mathrm{P} 1$ the majority of actin filament material becomes localized along the lateral membranes.

Immediately after the redistribution of actin filaments the glands begin to shrink rapidly. The actin filaments along the lateral cell boundaries may be involved in this process. The shrinkage is most apparent near the cell boundaries, which gives the outer surface of the gland an irregular wrinkled appearance, and may be a consequence of the tension of the actin filament-rich cortical layer after the counterbalance produced by the microtubule cell support diminishes (Ingbar, 1993). However, the persistence of the rearranged microfilaments may be necessary, since in at least some mammalian cells integrity of the actin filament system is necessary for fragmentation of apoptotic cells and formation of apoptotic bodies (Cotter et al, 1992).

The redistribution of actin filament material in apoptotic cells is likely to be associated with specific proteolysis of the components of actin filament system (Martin and Green, 1995). In at least one case it has been demonstrated that a microfilament-associated target protein (Gas2) is cleaved specifically by the ICE-like protease activated during apoptosis (Brancolini et al, 1995). Active involvement of actin filaments in the shrinkage of Drosophila salivary glands during PCD could be verified by treatment with drugs interfering with actin filament polymerization such as cytochalasin D. However, such experiments could not be performed given the current lack of a relevant in vitro system. Such a system is now under development in our laboratory.

Shortly after the onset of P1 (about $2 \mathrm{~h}$ ) actin filaments began to accumulate deeper in the cytoplasm. First they were visible as dots and patches but later they formed distinct spheres, presumably actin filament-coated vacuoles. Similar structures were described in lepidopteran silk glands where they appear during molting after silk secretion has stopped (Henderson and Locke, 1992). The authors proposed that the actin coat may be a means by which the actin filaments are stored during molting or that the coat is required for formation of endocytotic vacuoles. We provide evidence that the actin filament-coated organelles in the cells of Drosophila salivary glands may be related or identical to autophagic vacuoles. The overall lysosomal activity gradually increases and redistributes from small loci scattered throughout the cytoplasm to larger vesicles concentrated around nuclei, and is known to accumulate in the gland cells of the late third instar insects (von Gaudecker and Schmale 1974; Thomopoulos et al, 1992; Jones and Bowen, 1993). This distribution is similar to that seen for the actin coated vesicles. As revealed by electron microscopy, in the early third instar cells the acid phosphatase activity is mainly localized in the trans Golgi network and primary lysosomes. During L1 and L2 stages it redistributes to all Golgi stacks, secondary lysosomes and autophagic vacuoles (Thomopoulos et al, 1992). After puparium formation (P1) the autophagic vacuoles contain the bulk of acid phosphatase activity

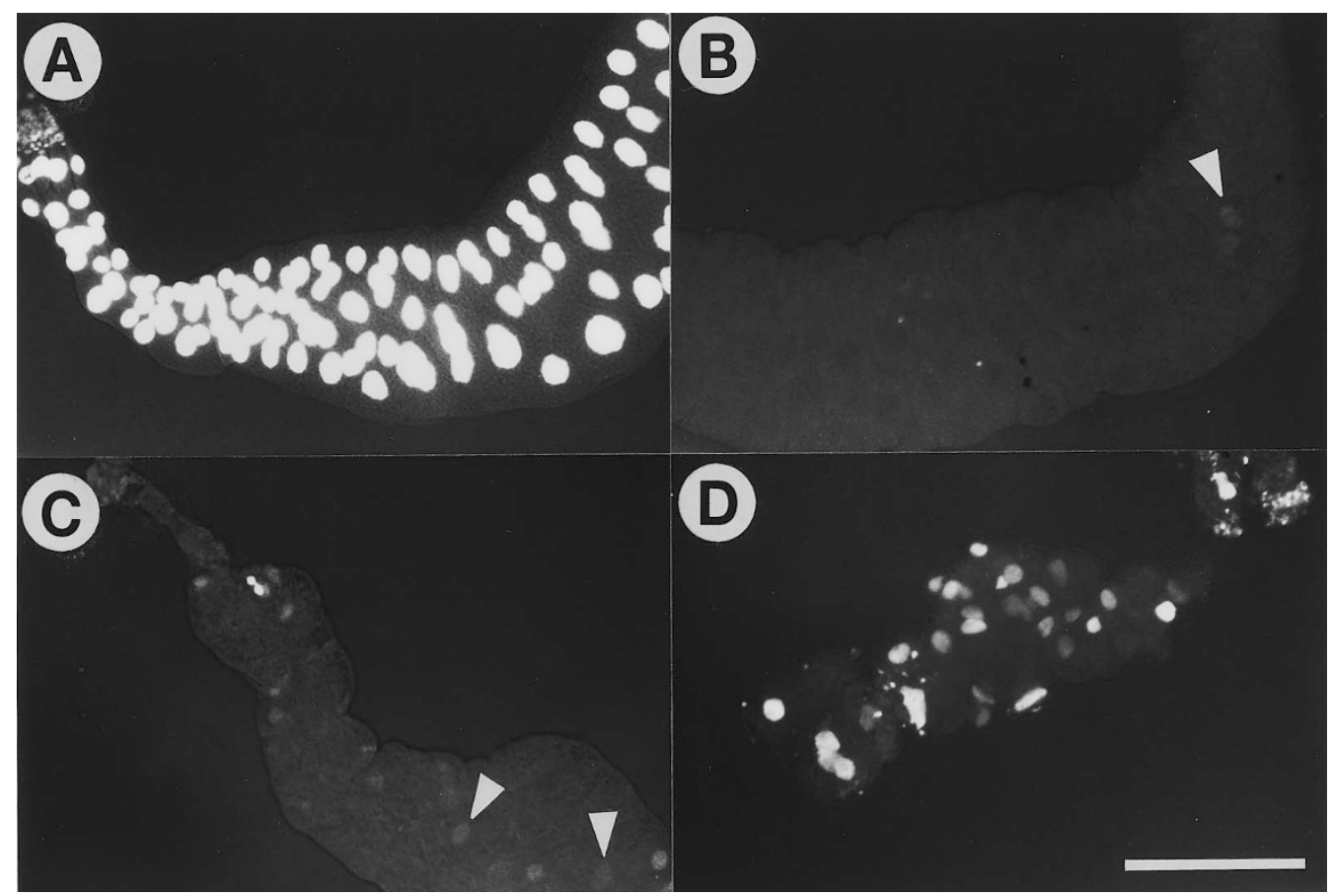

Figure 6 TUNEL labeling of fragmented DNA in Drosophila salivary glands. (A) Positive control, the gland from wandering larva preincubated with DNase I. (B) A gland $10 \mathrm{~h}$ after P1. (C) A gland $11 \mathrm{~h}$ after P1. (D) A gland $13 \mathrm{~h}$ after P1. Reaction was negative to very weak in the glands before $13 \mathrm{~h}$ after $\mathrm{P} 1$ (arrowheads). Bar, $500 \mu \mathrm{m}$. 
and continue to increase in volume (von Gaudecker and Schmale 1974). In our hands large patches of acid phosphatase reaction product concentrate around nuclei within 8-10 $\mathrm{h}$ after $\mathrm{P} 1$, at the same time that the actin filament-coated organelles form distinct perinuclear rings. Moreover, at the final stages of the salivary gland PCD isolated rounded cell fragments are loosely attached to the gland remnants. The surface of these structures gives continuous F-actin staining as well as intense acid phosphatase reaction.

In most systems apoptosis is associated with early nuclear DNA fragmentation accompanied with nuclear fragmentation. (Lockshin and Zakeri, 1991; Bortner et al, 1995). In Drosophila salivary glands DNA does not fragment until the late stage of PCD, approximately $11 \mathrm{~h}$ after $\mathrm{P} 1$, that is about $1 \mathrm{~h}$ after the nuclei are fully surrounded by lysosomes and autophagic vacuoles. Extensive fragmentation of nuclei occurs only at very late in PCD, $13 \mathrm{~h}$ after P1. It has been suggested previously (Zakeri et al, 1993, 1995; Bowen et al, 1993) that at least some insect tissues do not undergo early DNA fragmentation during PCD. Proteases and nucleases are responsible for apoptotic DNA fragmentation (Weaver et al, 1994; Martin and Green, 1995). DNase 1, which is considered to be one of the major endonucleases responsible for apoptotic chromosomal DNA fragmentation (Peitsh et al, 1993), may be stored in latent form in cells susceptible to apoptosis. It has been proposed that the enzyme gains access to the nucleus due to breakdown of the nuclear envelope (Peitsh et al, 1993). The timing of the late events of PCD in Drosophila salivary glands favors this idea. Therefore, the late degradation of nuclear material may be related to the autophagic nature of the $P C D$, in contrast to the condensation-fragmentation based apoptosis in most mammalian systems (Beaulaton and Lockshin, 1982, Zakeri et al, in preparation).

The changes in the cytoskeleton substantially precede DNA degradation and, if Drosophila salivary glands prove to be similar to the labial glands of tobacco hornworms, the changes in cytoskeleton may coincide with the earliest metabolic changes in programmed cell death. It is probable that alterations to microtubules and microfilaments are one of the sources of the rearrangement of cell shape. Whether they represent a mechanism by which cell function is disrupted or a consequence of other changes can best be tested when this form of PCD is duplicated in vitro. Such experiments are underway.

\section{Materials and Methods}

\section{Rearing conditions and timing of animals}

Drosophila melanogaster (Canton-S wild type) larvae were used in all experiments. Larvae were reared on Formula 4-24 instant Drosophila medium (Carolina) at $25^{\circ} \mathrm{C}$ with a $12 \mathrm{~h}$ photoperiod. The staging of the larvae was based on their physiological characteristics according to Ashburner (1989). Glands were isolated at the defined Ashburner stages: late 3 rd instar feeding larva $(F)$, wandering larva $(W)$, postfeeding larva (L1), stage L2 (shortened body, spiracles everted) and from white pupa (white puparium formed, $\mathrm{P} 1$ ) at $2 \mathrm{~h}$ intervals until their final collapse at $13.0-13.5 \mathrm{~h}$ after $\mathrm{P} 1$.

\section{Immunofluorescence of tubulin}

Glands were dissected in $0.9 \% \mathrm{NaCl}$, fixed in $4 \%$ formaldehyde in PEM buffer ( $60 \mathrm{mM}$ PIPES, $5 \mathrm{mM}$ EGTA, $5 \mathrm{mM} \mathrm{MgCl}_{2}$, pH 6.9) for 30 min, washed $3 \times 5$ min in PEM and permeabilized with $0.4 \%$ Triton $\mathrm{X}-100$ in PEM for $10 \mathrm{~min}$ at room temperature, washed in PEM, preincubated in $1 \%$ BSA and $0.2 \%$ Triton X-100 in PEM for $30 \mathrm{~min}$ at room temperature, and then incubated overnight with monoclonal anti$\alpha$-tubulin antibody (Amersham, 100X diluted in 1\% BSA in PEM) at $4^{\circ} \mathrm{C}$. After 3 washings in PEM and 1 in $1 \%$ BSA in PEM the glands were transferred into FITC-conjugated anti-mouse IgG (Calbiochem, diluted $5 \times$ in $1 \%$ BSA in PEM and preadsorbed overnight with fixed and permeabilized glands) and incubated for $3 \mathrm{~h}$ at room temperature. The glands were then washed $3 \times 5 \mathrm{~min}$ in PEM, incubated for $10 \mathrm{~min}$ in $1 \mu \mathrm{g} / \mathrm{ml}$ DAPI (Sigma) in PEM, washed and mounted in SlowFadeLight Antifade in $50 \%$ glycerol (Molecular Probes). The specimens were observed through use of a Nikon fluorescence microscope using fluorescein and DAP1 filters.

\section{Fluorescence labeling of actin filaments}

Glands were dissected and fixed as above, permeabilized with $1 \%$ Triton X-100 in PEM for $10 \mathrm{~min}$ at room temperature, washed $2 x$ in PEM and incubated with $5 \mu \mathrm{g} / \mathrm{ml}$ TRITC-conjugated phalloidin (Sigma) in PEM for $10 \mathrm{~min}$ at room temperature. The glands were then washed $3 \times 5 \mathrm{~min}$ in PEM, incubated for $10 \mathrm{~min}$ in $1 \mu \mathrm{g} / \mathrm{ml}$ DAPI (Sigma) in PEM, washed, mounted in $80 \%$ glycerol in PEM with $1 \mathrm{mg} / \mathrm{ml}$ paraphenylenediamine and observed as above.

\section{Detection of DNA fragmentation}

DNA fragmentation was visualized using the TUNEL technique (Gavrieli et al, 1992). Glands were isolated and fixed as described above. After fixation they were permeabilized $10 \mathrm{~min}$ in $1 \%$ Triton X100 in PEM and washed $3 \times 5$ min in PEM and once in DNase buffer (50 mM Tris- $\mathrm{HCl}, 10 \mathrm{mM} \mathrm{MgCl}, 0.1 \%$ Triton X-100). Some glands from wandering larvae were then incubated with $146 \mu \mathrm{g} / \mathrm{ml}(10.07 \mathrm{U} /$ $\mu \mathrm{g}$ ) of DNase I (Sigma) in a humidified chamber at $37^{\circ} \mathrm{C}$ for $1 \mathrm{~h}$ as a positive control. The glands were then incubated in TUNEL mixture for analysis by fluorescence microscopy (Boehringer Mannheim) in a humidified chamber at $37^{\circ} \mathrm{C}$ for $4 \mathrm{~h}$. They were then washed $4 \times 5 \mathrm{~min}$ in DNase buffer and mounted in SlowFade-Light Antifade in 50\% glycerol (Molecular Probes). Some of the DNase I-treated glands were incubated only in FITC-labeled nucleotide mixture without deoxynucleotidyl transferase (Boehringer Mannheim) as a negative control.

\section{Localization of acid phosphatase}

The glands were isolated, fixed and permeabilized as described for actin staining. Then they were incubated for $15 \mathrm{~min}$ at room temperature in acid phosphatase staining mixture (Acid Phosphatase Detection Kit, Sigma) prepared according to the manufacturer's instructions. After staining the glands were rinsed $3 \times 5$ min in distilled water and mounted in $80 \%$ glycerol. The acid phosphatase activity was detected microscopically by the presence of the insoluble redviolet reaction product.

\section{Acknowledgements}

This research was supported by a grants to RAL and ZZ (NIA RO110101) and to $Z Z$ (KO4) from the National Institute on Aging. 


\section{References}

Ashburner M (1989) Drosophila. A Laboratory Handbook. CSHL Press, New York. Beaulaton $\mathrm{J}$ and Lockshin RA (1982) The relation of programmed cell death to development and reproduction: comparative studies and attempt at classification. Int. Rev. Cytol. 29: 215-235

Bortner CD, Oldenburg NBE and Cidlowski JA (1995) The role of DNA fragmentation in apoptosis. Trends Cell Biol. 5: 21-26

Bowen ID, Morgan SM and Mullarkey K (1993) Cell death in the salivary glands of metamorphosing Calliphora vomitoria. Cell Biology International Reports 17 $13-34$

Brancolini CM, Benedetti M and Schneider C (1995) Microfilament reorganization during apoptosis: The role of Gas2, a possible substrate for ICE-like proteases. EMBO J. 14: 5179-5190

Carraway KL and Carraway CAC (1989) Membrane-cytoskeleton interactions in animal cells. Biochim. Biophys. Acta 988: 147-171

Cotter TG, Lennon SV, Glynn JM and Green DR (1992) Microfilament-disrupting agents prevent the formation of apoptotic bodies in tumor cells undergoing apoptosis. Cancer Res. 52: 997-1005

Dayton WR, Schollmeyer JV, Lepley RA and Cortes LR (1981) (Abstract) A calciumactivated protease possibly involved in myofibrillarprotein turnover. Isolation of a low-calcium-requiring form of the protease. Biochim. Biophys. Acta. 659: 48-61

Gavrieli Y, Sherman Y and Ben-Sasson SA (1992) Identification of programmed cell death in situ via specific labeling of nuclear DNA fragmentation. J. Cell Biol. 119 493-501

Halaby R, ZakeriZand Lockshin RA (1994) Metabolic events during programmed cell death in insect labial glands. Biochem. Cell Biol. 72: 597-601

Harrod MJE and Kastritsis CD (1972) Developmental studies in Drosophila. II. Ultrastructural analysis of the salivary glands of Drosophila pseudoobscura during some stages of development. J. Ultrastruct. Res. 38: 482-499

Hengartner MO (1994) A rich harvest. The identification of genes that affect programmed cell death in Drosophila puts this organism at the forefront of celldeath research. Curr. Biol. 4: 950-952

Henderson SC and Locke M (1992) The redeployment of F-actin in silk glands during moulting. Cell Motil. Cytoskel. 21: 101-110

Ingbar DE (1993) Cellular tensegrity: defining new rules of biological design that govern the cytoskeleton. J. Cell Sci. 104: 613-627

Jewell SA, Bellomo G, Thor H, Orrenius S and Smith MT (1992) Bleb formation in hepatocytes during drug metabolism is caused by disturbances in thiol and calcium ion homeostasis. Science 217: 1257-1259

Jones HE and Bowen ID (1993) Acid phosphatase activity in the larval salivary glands of developing Drosophila melanogaster. Cell Biol. Int. 17: 305-315

Kumar S (1995) ICE-like proteases in apoptosis. Trends Biochem. Sci. 20: 198-202

Lockshin RA (1981) Cell death in metamorphosis. In Cell Death in Biology and Pathology (ed. ID Bowen and RA Lockshin), pp. 79-121. Chapman and Hall, London

Lockshin RA and Zakeri Z (1991) Programmed cell death and apoptosis. In Apoptosis:: The Molecular Basis of Cell death (ed. LD Tomei and FO Cope), pp. 47-60. Cold Spring Harbor Laboratory Press, New York

Majno $G$ and Joris I (1995) Apoptosis, oncosis, and necrosis. An overview of cell death. Am. J. Pathol. 146: 3-15

Martin SJ and Cotter TG (1990a) Specific loss of microtubules in HL-60 cells leads to programmed cell death (apoptosis). Biochem. Soc. Trans. 18: 299-301

Martin SJ and Cotter TG (1990b) Disruption of microtubules induces an endogenous suicide pathway in human leukemia HL-60 cells. Cell Tissue Kinet. 23: 545-549

Martin SJ and Green DR (1995) Protease activation during apoptosis: death by a thousand cuts? Cell 82: 349-352

Martin SJ, Green DR and Cotter TG (1994) Dicing with death: dissecting the components of the apoptotic machinery. Trends Biochem. Sci. 19:26-30
Martin SJ, O'Brien GA, Nishioka WK, McGahon AJ, Mahboubi A, Saido TC and Green DR (1995) Proteolysis of fodrin (non-erythroid spectrin) during apoptosis. J. Biol. Chem. 270: 6425-6428

Nicotera P and Orrenius S (1992) $\mathrm{Ca}^{2+}$ and cell death. Ann NY Acad Sci. 648: 17-27

Peitsch MC, Polzar B, Stephan H, Crompton T, MacDonald HR, Mannherz HG and Tschopp J (1993) Characterization of the endogenous deoxyribonuclease involved in nuclear DNA degradation during apoptosis (programmed cell death). EMBO J. 12: $371-377$

Pittman SM, Strickland D and Ireland CM (1994) Polymerization of tubulin in apoptotic cells is not cell cycle dependent. Exp. Cell Res. 215: 263-272

Poels CLM, de Loof A and Berendes HD (1971) Functional and structural changes in Drosophila salivary gland cells triggered by ecdysterone. J. Insect. Physiol. 17: $1717-1729$

Raff MC, Barres BA, Burne JF, Coles HSR, Ishizaki Y and Jacubson MD (1994) Programmed cell death and the control of cell survival. Phil. Trans. R. Soc. London B 345: 265-268

Riparbelli MG, Callaini G and Dallai R(1993) Spatial organization of microtubules and microfilaments in larval and adult salivary glands of Drosophila melanogaster. Tissue Cell 25: $751-762$

Schroer TA and Sheetz MP (1991) Functions of microtubule-based motors. Annu. Rev. Physiol. 53: 629-652

StellerH(1995) Mechanisms and genes of cellular suicide. Science 267: 1445-1449

Takano Y, Okudaira M and Harmon BV (1993) Apoptosis induced by microtubule disrupting drugs in cultured human lymphoma cells. Inhibitory effects of phorbol ester and zine sulphate. Pathol. Res. Pract. 189: 197-203

Thomopoulos GN, Neophytou EP, Alexiou M, Vadolas A, Limberi-Thomopoulos S and Derventzi A (1992) Structural and histochemical studies of Golgi complex differentiation in salivary glands cells during Drosophila development. J. Cell Sci. 102: $169-184$

Thomopoulos GN, Neophytou EP and Kastritsis CD (1989) An ultrastructural and histochemical development study of Drosophila auraria salivary gland cells during the third-instar period. Can. J. Zool. 67: 421-429

Tsukidate K, Yamamoto K, Snyder JW and Farber JL (1993) Microtubule antagonists activate programmed cell death (apoptosis) in cultured rat hepatocytes. Am. J. Pathol. 143: $918-925$

Voelkel-Johnson C, Entingh A, Wold WSM, Gooding LR and Laster SM (1995) Activation of intracellular proteases is an early event in TNF-induced apoptosis. J. Immunol. 154: 1707-1716

von Gaudecker B and Schmale EM (1974) Substrate histochemical investigations and ultrahistochemical demonstrations of acid phosphatase in larval and prepupal salivary glands of Drosophila melanogaster. Cell. Tissue Res. 155: $75-89$

Watt JA, Pike CJ, Walencewicz-Wasserman AJ and Cotman CW (1994) Ultrastructural analysis of $\beta$-amyloid-induced apoptosis in cultured hippocampal neurons. Brain Res. 661: 147-156

Weaver VM, Lach B, Walker PR and Sikorska M (1994) Role of proteolysis in apoptosis: involvement of serine proteases in internucleosomal DNA fragmentation in immature thymocytes. Biochem. Cell Biol. 71: 488-500

Wyllie AH, Kerr JFR and Currie AR (1980) Cell death: The significance of apoptosis. Int. Rev. Cytol. 68: 251-306

Yuan J, Shaham S, Ledoux S, Ellis HM and Horvitz HR (1993) The C. elegans cell death gene ced-3 encodes a protein similar to mammalian interleukin-1 $\beta$ converting enzyme. Cell 75: 641-652

Zakeri Z, Bursch W Tenniswood M and Lockshin RA (1995) Cell death: programmed, apoptosis, necrosis, or other? Cell Death Differ. 2: 87-96 